question of responsibility. Now, for the life of me I cannot see why he should be so anxious over this point, especially as I myself can observe other points in my scheme which would seem to call for more insistent questioning-as they might be viewed from the standpoint of critics. I refer your correspondent to the division of responsibility as it obtains between a medical practitioner and either his qualified assistant or his trained medical or surgical nurse. Moreover, it should be in the power of an appointed district obstetric practitioner to dismiss any registered obstetric nurse for malpraxis or certain irregularities at a moment's notice, and such dismissal should be followed by inquiry and loss of certificate if the offence were considered sufficiently serious, But whoever hears of serious malpraxis on the part of either an assistant or a qualified medical or surgical nurse? The circumstances under which chief and subordinate work practically forbid it; and so it would be with the properly qualified registered obstetric furse. I would draw your correspondent's attention to the fact that $I$ gave no fees as appropriate to a Bill. I never mentioned the word Bill in my scheme or in paragraphs referring to that scheme. The whole question of right adjustment of all fees is one for after-consideration, the main question being, Does it seem feasible that midwives should be replaced by the coöperative working of medical man plus obstetric nurse?

To the question, "What is the intended effect of the medical man's visit as suggested in the latter paragraph of Clause 4?" I answer that the visit would be one made in order to confirm or not the obstetric nurse's opinion and the patient's belief that she is in a satisfactory condition-a simple confirmative and disciplinary visit, to satisfy everybody and to remind the nurse that her finished work is subject to the inspection of a medical man. Mr. Flemming is labouring under an apprehension regarding Clause 7. He forgets that the working-classes would not be obliged to retain the joint services of an appointed medical man and obstetric nurse, for they would be at liberty to engage an ordinary practitioner if they chose. Under my suggested scheme I do not expect quite every woman to rush to the combination although I do believe that more would take advantage of it than of a midwife as we now understand her, and thus a badly paid and to many practitioners an undesirable class of work (so they say) would be diminished in amount. Likewise Mr. Flemming's anticipation of " complications between neighbours and the difficulties of enforcing the rule" is one of an alarmist. Consultations would never be held with other local general practitioners, but with outside consultants of standing, as rarely as they would be required, and the appointed obstetric practitioner would go on with the case afterwards. The appointment of obstetrioians would take place annually. Women of the general public would not be obliged to engage the combination, supposing either a medical man or a nurse were unpopular.

$$
\text { I am, Sirs, yours faithfully, }
$$

London, Feb. 3rd, 1900 HAYDN BROWN.

\section{CONTAMINATED COCKLES.}

\section{To the Editors of THE LANCET.}

SIRs,-You are no doubt aware that we had in the city of Belfast in 1898 what might have been considered an epidemic of typhoid fever, and if now the number of cases reported has fortunately very materially decreased we still have more cases amongst us, compared with the other parts of the United Kingdom, than would be considered normal. Notwithstanding the most diligent inquiries the local authorities and the local medical profession have failed to trace the origin of the epidemic. I suggested from time to time that the sale of cockles, collected on the shores of estuaries contaminated by sewage, was perhaps one of the sources which would account for the prevalence of typhoid fever in Belfast. Cockles are mostiy consumed here by the poorer classes and these classes seem to furnish more than their proportion of typhoid fever cases. We have in Belfast about 700 Jews, mostly of Russian origin and poor, who all strictly adhere to the Mosaic code of diet, discarding amongst other food all animals living in the sea not covered by scales. As President of the Hebrew community here I have made inquiries and no case of typhoid fever has been reported amongst the members of the congregation for many years past.

My object in bringing the matter before you is to draw attention to this fact, and if similar experience is recorded elsewhere you will no doubt use your powerful influence in connexion with the other members of the medical press to obtain some legislation to prohibit the collection of cockles and oysters from any estuary that might be contaminated by sewage.

Belfast, Feb. 5tb, 1900

I am, Sirs, yours truly, OTIO JAFFE.

\section{THE DURATION OF THE IMMUNITY CON- FERRED BY INOCULATION AGAINST TYPHOID FEVER. \\ To the Editors of THE LANCET.}

SIRs,-In a leading article on Anti-typhoid Inoculation in THE LANCET of Jan. 27 th you state that "it is necessary that the effects should last for a considerable period. On this point we have as yet little information." This raises the question whether we have any scientific data or guide to fix approximately the effect of this or any other inoculation.

It appears to me that there is one circumstance which might and does help us in coming to some conclusion. Dr. W. B. Ransom in his address on "Immunity to Disease" says, "In small-pox, scarlet lever, measles, syphilis, the protection is considerable and long; in typhoid fever it is fairly well marked; in diphtheria more transient; while in pneumonia, erysipelas. influenza, and cholera it is hardly at all apparent." of course he means an attack of disease naturally acquired and which confers immunity. This may be in diseases naturally acquired. I think in inoculation the period of incubation of disease does help us in coming to some conclusion on the subject. In those diseases in which the period of incubation is longer the effect of inoculation is also longer. One hears a good deal about plague and cholera inoculations. I think the effect of inoculations in these cases must be very transient in men. We are told to look at the statistics. As we all know, statistics can prove anything. What we as scientific men want is scientific explanation to guide us. It further appears to me that inoculation that takes a long time in producing its effect-viz., malaise, fever, \&c.-confers immunity which ought to last for a long time too. This leads us to another conclusion. Inoculation can confer a longer immunity only in those diseases in which progress of the disease and morbid changes in the organs or glands which they particularly affect are slow and gradual. In those diseases in which progress is very rapid inoculation cannot be of any advantage such as plague, cholera, and influenza.

For these reasons I venture to think that " anti-typhoid inoculation" will prove of great service, but there should be two or three inoculations at intervals before a marked and permanent effect is produced. Though it has been demonstrated that immunity is due to a vital action of the cells of the body, alteration, however slight, in stracture of glands affected has something to do with it. Of all the diseases in which inoculations have been performed in only two of them is there a marked benefit-vaccination against small-pox and inoculation against rabies. The reason is that entire lymph in one case and emulsion of the entire substance of the medulla oblongata in the other are used, and not dead bacilli toxins or proteins separately. It shows that to have any marked effect there should be something. more than "anti-infective" or " antitoxin" substances.

Copeman seems to have found the micro-organism of variola, I think, for practical purposes, it will be an evil day for science and humanity if such a bacillus is isolated and we leave off using vaccine lymph as protection against small-pox. I am, Sirs, yours faithfully,

Portley, Caterham, Feb. 4th, 1900. $\quad$ P. J. DAmanis, D.P.H.

\section{"DEATHS UNDER CHLOROFORM." \\ To the Editors of THE LANCET.}

SIRs,-If Mr. Whiteford will do me the honour to reconsider what I have endeavoured to set out in the three cited recent numbers of THE IAANCET he will find that the apposition of facts has answered his question by demolishing the proposition on which it is based. But there is no difficulty in giving a categorical reply. Speaking of the open or Skinner's mask method of administration, Mr. Whiteford's question is: "If the patient coes not absorb a similar dose 